\title{
Treatment Planning
}

National Cancer Institute

\section{Source}

National Cancer Institute. Treatment Planning. NCI Thesaurus. Code C162700.

The process of developing an appropriate therapeutic strategy for a patient. 